\title{
EFEITO DA TEMPERATURA DE RECOZIMENTO SOBRE A MICROESTRUTURA E AS PROPRIEDADES MECÂNICAS DO AÇO ARBL MICROLIGADO NBR 6656 LNE 380
}

\author{
Éricky Ferreira Rangel Gomes, Mayra Adriana Lima Viana Henrique Lessa ${ }^{1}$, Michelle dos Reis \\ Riscado Lourenço ${ }^{1}$ e Bárbara Ferreira de Oliveira ${ }^{2 *}$
}

\begin{abstract}
RESUMO
GOMES, E.F.R.; LESSA, M.A.L.V.H.; LOURENÇO, M.R.R.; OLIVEIRA, B.F. Efeito da Temperatura de Recozimento sobre a Microestrutura e as Propriedades Mecânicas do Aço ARBL microligado NBR 6656 LNE 380. Perspectivas Online: Exatas \& Engenharias, v. 7, n.18, p.09-14, 2017.

Neste trabalho objetiva-se avaliar a microestrutura e as propriedades mecânicas de um aço ARBL microligado recebida na condição laminada e após recozimento a $950{ }^{\circ} \mathrm{C}$ e $1150{ }^{\circ} \mathrm{C}$. A microestrutura foi analisada por meio da técnica de microscopia confocal e as micrografias foram utilizadas para análise quantitativa do tamanho dos grãos. As propriedades mecânicas obtidas foram determinadas por meio de ensaios de tração. Foi

observado que em todas condições a microestrutura é constituída de ferrita e perlita, mas que os tamanhos de grãos ferríticos são diferentes e que os tratamentos térmicos promoveram a queda da tensão de escoamento e da resistência à tração. No entanto, verificou-se que um dos tratamentos térmicos resultou num tamanho de grão mais próximo ao tamanho de grão encontrado na condição recebida.
\end{abstract}

Palavras-chave: Aço microligado; Recozimento; Microestrutura; Propriedades Mecânicas. 


\begin{abstract}
The objective of this work is to evaluate the microstructure and the mechanical properties of a microalloyed HSLA steel received in rolled condition and after annealing at $950{ }^{\circ} \mathrm{C}$ and 1150 ${ }^{\circ} \mathrm{C}$. The microstructure was analyzed using confocal microscopy technique and the micrographs were used for quantitative analysis of grain size. The mechanical properties were

verified that under all conditions the microstructure is composed of ferrite and perlite, but the ferritic grain sizes are different and that heat treatments promoted the decrease of yield stress and tensile strength. However, it has been found that one of the heat treatment resulted in a grain size closer to the size found in the condition as received.
\end{abstract} determined by means of tensile tests. It was

Keywords: Microalloyed steel; Annealing; Microstructure; Mechanical Properties.

${ }^{1}$ Institutos Superiores de Ensino do CENSA - ISECENSA - Acadêmico do Curso de Graduação em Engenharia de Produção - Rua Salvador Correa, 139, Centro, Campos dos Goytacazes, RJ, CEP: 28035-310, Brasil;

${ }^{2}$ Institutos Superiores de Ensino do CENSA - ISECENSA - Laboratório de Engenharia - Rua Salvador Correa, 139, Centro, Campos dos Goytacazes, RJ, CEP: 28035-310, Brasil;

(*)e-mail: barbara.fo@gmail.com

Data de chegada: 20/05/2017 Aceito para publicação: 28/07/2017 


\section{INTRODUÇÃO}

A demanda por aços que apresentassem maior tenacidade, soldabilidade resistência mecânica e à corrosão atmosférica em relação ao aço carbono promoveu o desenvolvimento dos aços de alta resistência e baixa liga (ARBL) microligados no início do século XX. Desde então, estes aços vêm sendo aplicados amplamente nos setores petrolíferos, naval e automobilístico. Geralmente, quase todos os aços frequentemente passam por uma rota de produção que envolve solidificação, reaquecimento (encharque) e conformação plástica. Sendo assim, é importante estudar o efeito dos parâmetros envolvidos nestes processos sobre a microestrutura e propriedades mecânicas (ASM HANDBOOK COMMITEE, 1990; BOTT et al., 2005).

Nos aços ARBL, devido à presença de elementos microligantes, tais como vanádio (V), nióbio $(\mathrm{Nb})$ e titânio ( $\mathrm{Ti}$ ), pode-se empregar temperaturas de encharque maiores possibilitando que laminadores menos potentes sejam utilizados. Estes elementos formam carbetos, nitretos e carbonitretos que atuam no retardo do crescimento de grão austenítico e/ou ferrítico e por isso resultam em tamanhos de grão finais menores. No entanto, foi encontrado que pode existir uma diferença substancial entre a força de bloqueio dos precipitados de carbetos, nitretos e carbonitretos de nióbio entre as regiões dendríticas e interdendríticas. Consequentemente, durante o reaquecimento, a mobilidade do contorno da austenita é bloqueada de forma heterogênea resultando na formação de grãos com distribuição bimodal e propriedades mecânicas heterogêneas caso a temperatura utilizada encontre-se abaixo da temperatura de dissolução dos precipitados (DAVIS, 2001; CHAKRABARTI et al., 2005).

Neste trabalho busca-se estudar o efeito da temperatura de recozimento na microestrutura e no comportamento em tração de um aço ARBL microligado a fim de verificar qual temperatura se mostra mais favorável para o emprego como temperatura de encharque.

\section{METODOLOGIA}

Nesta pesquisa foram utilizadas amostras de uma chapa de aço microligado ARBL NBR 6656 LNE $380(600 \mathrm{~mm} \times 500 \mathrm{~mm} \times 6 \mathrm{~mm})$, que na condição como recebida (condição 1) apresenta-se laminada a quente. Esta amostra foi cortada utilizando-se uma serra elétrica gerando 18 amostras com aproximadamente $100 \mathrm{~mm} \times 25 \mathrm{~mm} \times 6 \mathrm{~mm}$, divididas igualmente em amostras com o comprimento paralelo à direção de laminação (L) e à direção transversal à laminação (LT).

Foi utilizado para os tratamentos térmicos de recozimento o forno do tipo mufla QUIMIS Q318S. O tratamento foi realizado a uma temperatura de $950{ }^{\circ} \mathrm{C}$ (condição 2) e $1150^{\circ} \mathrm{C}$ (condição 3 ), ambos durante $1 / 2$ hora com resfriamento no forno.

A preparação metalográfica seguiu as etapas convencionais de embutimento, lixamento, polimento e ataque químico com uma solução de Nital 2\%. A caracterização microestrutural das amostras nas três condições foi realizada nos planos LTS por meio microscópio confocal OLYMPUS LEXT OLS4000. A partir das micrografias obtidas, foi realizada a contagem do tamanho médio de grão e determinado o tamanho de grão ASTM por meio dos padrões do intercepto linear e granulométrico linear utilizando três micrografias do plano perpendicular à direção de laminação. Os resultados do método granulométrico linear ainda foram utilizados na plotagem de um gráfico de um histograma (frequência versus intervalo do tamanho do grão) para avaliação do tipo de distribuição apresentado.

Persp. Online: exatas \& eng., Campos dos Goytacazes, 18 (07) 09 - 14 - 2017

seer.perspectivasonline.com br 
A fabricação dos corpos de prova e os ensaios de tração foram realizados segundo a norma ASTM E812 na máquina de ensaios EMIC DL-2000 com velocidade de deslocamento de 0,2 $\mathrm{mm} / \mathrm{min}$. para cada condição foram executados ensaios em 3 corpos de prova na direção L e LT.

\section{RESULTADOS}

Nas Figuras 1 a-c são apresentadas montagens tridimensionais da microestrutura nos planos LTS do aço NBR 6656 nas condições 1, 2 e 3, respectivamente. Observa-se que a microestrutura apresenta um certo bandeamento alternado de grãos de ferrita e perlita que pode ter sido causado pela segregação promovida durante a solidificação e um alongamento preferencial provocado pelo processo de laminação.

Após os tratamentos térmicos de recozimento notou-se que a microestrutura também apresenta como constituintes a ferrita e a perlita. Embora possa ser observado que após os tratamentos os grãos tornaram-se equiaxiais e maiores, na amostra recozida a menor temperatura $\left(950^{\circ} \mathrm{C}\right)$ notou-se ainda um certo bandeamento entre os dois constituintes presentes.
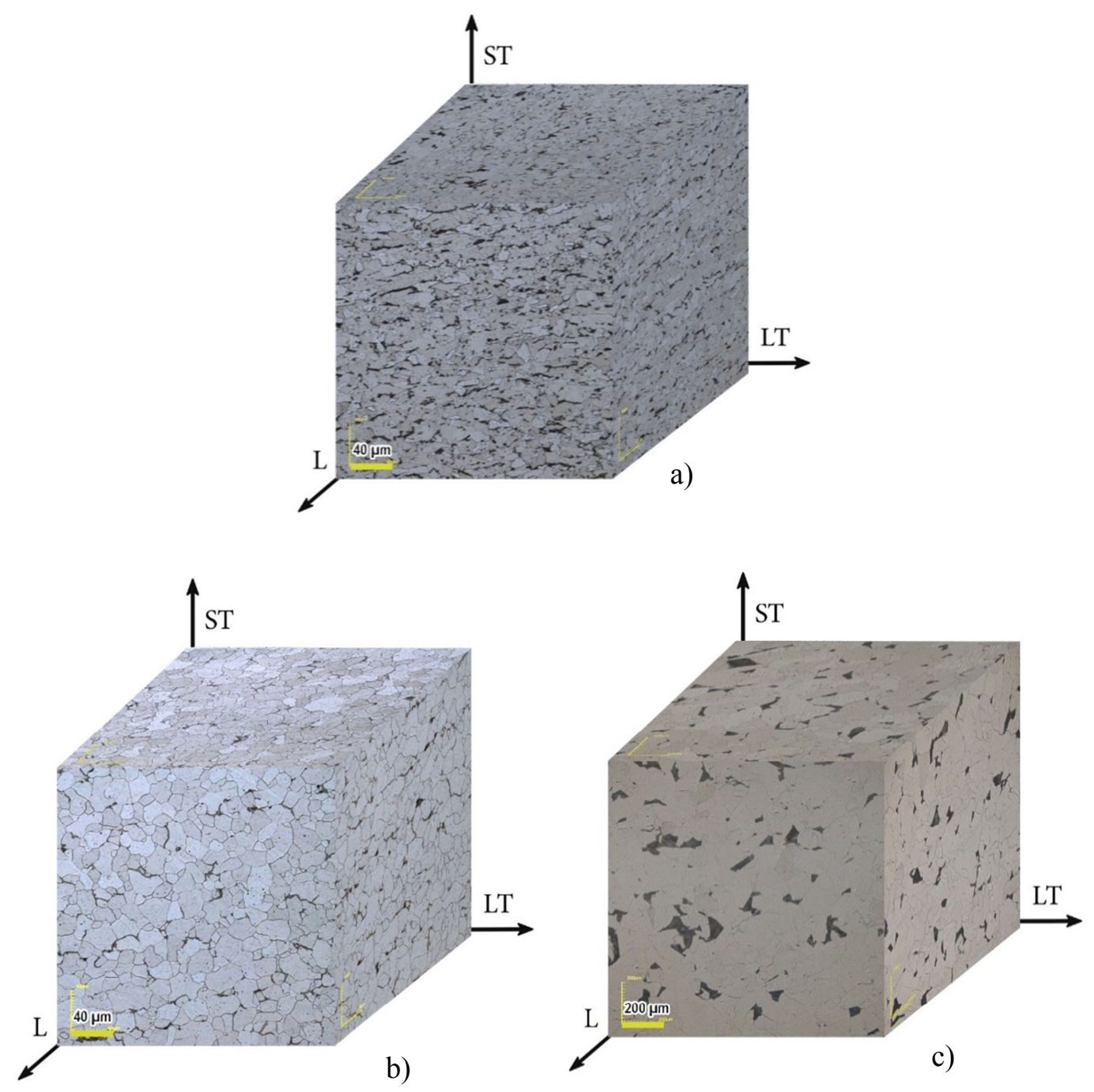

Figura 1. Montagem tridimensional da microestrutura nos planos LTS do aço NBR 6656 na condição a) 1 como recebida; b) 2 - recozida a $950{ }^{\circ} \mathrm{C}$; c) 3 - recozida a $1150{ }^{\circ} \mathrm{C}$ 
Na Tabela 1 são apresentados os valores do tamanho médio de grão e do tamanho de grão ASTM determinados por intermédio do método do padrão linear para cada condição estudada. Nota-se que, como observado nas micrografias apresentadas, houve um acréscimo do tamanho de grão após os tratamentos térmicos. Embora a condição 2 tenha produzido um aumento do tamanho de grão, o tamanho de grão ASTM encontrado mostrou-se próximo ao valor encontrado na condição 1. Isto indica que esta temperatura pode ser utilizada como temperatura de encharque. Este fato é favorável, visto que temperaturas mais baixas podem promover problemas nos laminadores industriais e que os grãos ainda poderiam ser refinados de forma eficaz por meio do processo de laminação controlada seguido de resfriamento rápido.

Tabela 1. Variáveis calculadas por meio do método do padrão linear para o aço NBR 6656 nas condições 1-3

\begin{tabular}{cccc}
\hline Variável & \multicolumn{3}{c}{ Condição } \\
& $\mathbf{1}$ & $\mathbf{2}$ & $\mathbf{3}$ \\
\hline Tamanho médio de grão $(\mu \mathrm{m})$ & 7,48 & 13,02 & 75,05 \\
Tamanho de grão $(\mathrm{TMG})$ & 11 & 10 & 5 \\
ASTM & & & \\
\hline
\end{tabular}

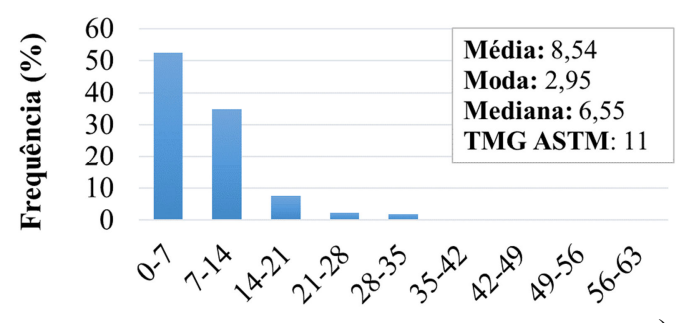

Intervalos de tamanho de grão

a)

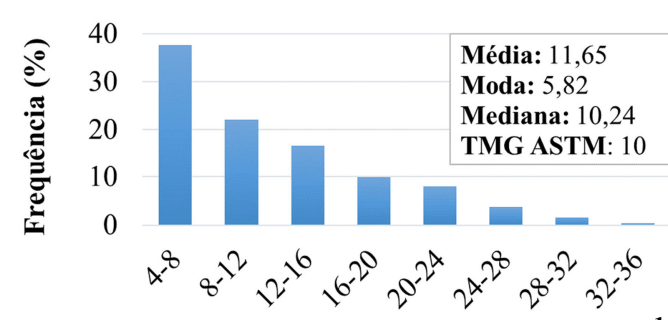

Intervalos de tamanho de grão

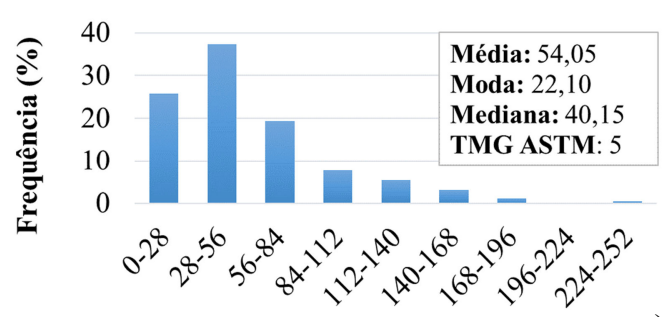

Intervalos de tamanho de grão c)

Figura 2. Histogramas da distribuição dos tamanhos de grãos do aço NBR 6656 nas condições a) 1 - como recebida; b) 2 -recozida a $950{ }^{\circ} \mathrm{C}$; c) 3 - recozida a $1150{ }^{\circ} \mathrm{C}$

Nas Figuras 2 a-c são apresentados os histogramas da frequência dos intervalos dos tamanhos de grãos da ferrita encontrados nas condições 1, 2 e 3, respectivamente. Apesar do método empregado nesta análise ser diferente, encontrou-se os mesmos valores do tamanho de grão ASTM. Em ambas as condições foram encontradas distribuições modais dos tamanhos de grãos.

Uma vez que os carbetos, nitretos e carbonitretos dos elementos microligantes são responsáveis pelo retardo do crescimento do grão em altas temperaturas, a distribuição do tamanho de grão encontrada indica que a precipitação ocorreu de forma homogênea na microestrutura. Este fato é importante para melhorar a confiabilidade do material durante o serviço. 
Os gráficos da Figura 3 apresentam os valores das propriedades encontradas por intermédio dos ensaios de tração realizados nas direções L e LT do aço NBR 6656 nas condições estudadas. Verifica-se que em todas condições não houve variação significativa das propriedades entre as direções estudadas, indicando que o material tem comportamento isotrópico. Os valores das propriedades mecânicas encontradas para o aço na condição como recebida seguem os padrões indicados pela ABNT NBR 6656.
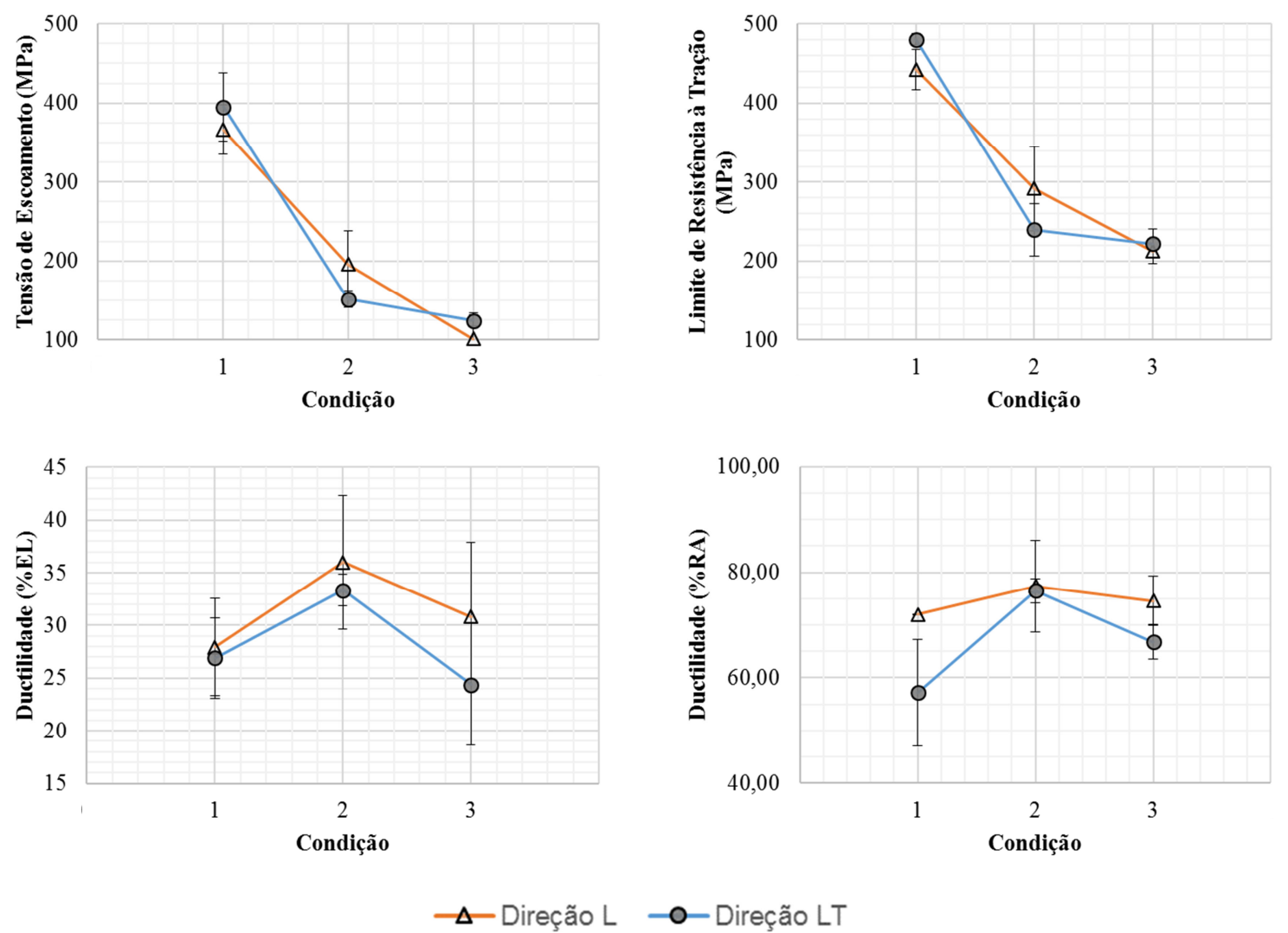

Figura 3. Variação da a) tensão de escoamento; b) limite de resistência à tração; c) ductilidade (\%EL); d) ductilidade (\%RA)

Conforme pode ser observado, os tratamentos térmicos promoveram a redução da tensão de escoamento e do limite de resistência à tração, de modo que, após qualquer um desses recozimentos, o aço já não poderia ser classificado como NBR 6656 do grau LNE 380. Embora grãos maiores promovam maior ductilidade do material, foi observada uma queda da ductilidade média na condição 3, que apresentou maior tamanho médio de grão. No entanto, estes valores encontram-se dentro de um intervalo de dispersão se enquadra com os valores encontrados na condição 2 .

\section{CONSIDERAÇÕES FINAIS}

Neste trabalho investigou-se a influência da temperatura de recozimento sobre a microestrutura e as propriedades mecânicas de um aço ARBL microligado, fornecido como NBR 6656 LNE 180. Foi possível verificar que o aço na condição como recebida apresenta uma microestrutura de grãos finos de ferrita e perlita e suas propriedades mecânicas enquadram-se aos valores especificados pela ABNT NBR 6656. Após os tratamentos de recozimento, observou-se a presença dos mesmos constituintes microestruturais. No entanto, notou-se que o tratamento térmico promoveu o aumento do tamanho médio de grão e que maiores temperaturas induzem a formação de grãos maiores. Tanto antes como após os tratamentos térmicos encontrou-se uma distribuição de tamanho de grão modal, indicando que os precipitados formados pelos elementos microligantes encontram-se distribuídos homogeneamente na microestrutura. Embora o tamanho 
de grão encontrado após o recozimento a $950{ }^{\circ} \mathrm{C}$ seja próximo ao tamanho de grão do aço na condição como recebida, os valores encontrados das propriedades mecânicas não foram suficientes para que o aço fosse enquadrado como NBR 6656. Contudo, este estudo indicou que a temperatura do tratamento de recozimento a $950{ }^{\circ} \mathrm{C}$ poderia ser utilizada para o encharque do material antes do processo de laminação controlada, visto que a microestrutura foi homogeneizada e não houve um crescimento excessivo do tamanho de grão.

Possivelmente, após este processo de conformação mecânica, o aço em questão apresentaria grãos de tamanhos ainda menores do que os tamanhos encontrados na condição como recebida, o que possibilitaria o aumento da resistência mecânica e da tensão de escoamento do material.

\section{REFERÊNCIAS}

AMERICAN SOCIETY FOR METALS. Handbook. Properties and Selection: Irons, Steels, and High-Performance Alloys. Materials Park: ASM International, 1990. 1 v.

ASTM E8. Standard Test Methods for Tension Testing of Metallic Materials. 2011.

BOTT, I. D. E. S., SOUZA, L. F. G. D. E., TEIXEIRA, J. C. G., RIOS, P. R. High-Strength Steel Development for Pipelines: A Brazilian Perspective. Metallurgical and Materials Transaction A, v. 36, p. 2005-443, 2005.

CHAKRABARTI, D., DAVIS, C. L., STRANGWOOD, M. Characterization of Bimodal Grain Structures and Their Dependence on Inhomogeneous Precipitate Distribution during Casting. Materials Science Forum, v. 501, p. 613-621, 2005.

DAVIS, J. R. Alloying: Understanding the Basics. Materials Park: ASM International, 2001. 647 p. 